\title{
Choriocarcinoma involving the pancreas as first manifestation of a metastatic regressing mixed testicular germ cell tumor
}

\author{
Lan Wang ${ }^{1}$, Martha B Pitman ${ }^{1}$, Carlos Fernandez-del Castillo ${ }^{2}$, Paula Dal Cin ${ }^{3}$ and \\ Esther Oliva ${ }^{1}$ \\ ${ }^{1}$ Department of Pathology; ${ }^{2}$ Department of Surgery, Massachusetts General Hospital and ${ }^{3}$ Department of \\ Pathology, Brigham and Women's Hospital, Harvard Medical School, Boston, MA, USA
}

\begin{abstract}
We describe an unusual case of metastatic choriocarcinoma of the pancreas arising from a regressing testicular mixed germ cell tumor that clinically mimicked a primary pancreatic tumor. A 54-year-old male presented with a 2-month history of progressive upper abdominal pain, weight loss, and jaundice. He also had a history of recurrent epididymitis associated with the presence of a right testicular mass shown to be cystic by ultrasound and stable for at least 10 years. A computed tomography scan showed an isolated $6 \mathrm{~cm}$ mass in the head of the pancreas. A pancreaticoduodenectomy was performed. Upon histological examination, the pancreatic tumor showed extensive hemorrhage and necrosis. In the viable area, the tumor was composed of an intimate mixture of mononuclear cytotrophoblast cells and multinucleated syncytiotrophoblasts with vascular invasion. These characteristic features led to the correct diagnosis on frozen section. The cytology of the tumor was nonspecific and suggested undifferentiated carcinoma of the pancreas. The trophoblastic origin of the tumor cells was confirmed by immunohistochemistry staining. The testicular mass showed a regressed mixed germ cell tumor of predominantly seminoma with focal teratoma but without a choriocarcinoma component. In conclusion, we present a rare and unusual case of a regressing testicular mixed germ cell tumor that presented as a primary pancreatic tumor. Cytological features of the pancreatic mass were not specific and raised the possibility of a primary undifferentiated carcinoma of the pancreas. Characteristic histological features of choriocarcinoma led to the correct diagnosis on frozen section. Subsequent resection of the testicular mass confirmed the presence of a cystic and scarring (regressing) mixed germ cell tumor but without evidence of choriocarcinoma. Modern Pathology (2004) 17, 1573-1580. doi:10.1038/modpathol.3800226
\end{abstract}

Keywords: choriocarcinoma; metastatic malignancy; pancreas; germ cell tumor; testis; regressing

Pure extragonadal nongestational choriocarcinoma is extremely rare with limited case reports. ${ }^{1-5}$ Only three cases of primary choriocarcinoma of the pancreas have been previously reported in the literature ${ }^{6-8}$ one of which was associated with a cystadenocarcinoma. ${ }^{7}$ Primary gonadal choriocarcinomas are also rare and they usually present with widespread disease, most commonly involving the lung, liver, and brain, but may rarely present as a solitary mass. A single case of pure gonadal choriocarcinoma presenting as a metastatic cystic neoplasm of the pancreas has been reported. ${ }^{9}$ Metastasis from a testicular mixed germ cell tumor as pure choriocarcinoma is also uncommon. ${ }^{10} \mathrm{We}$

Correspondence: Dr MB Pitman, MD, Department of Pathology, Massachusetts General Hospital, Harvard Medical School, 14 Fruit Street, Boston, MA 02114, USA.

E-mail: mpitman@partners.org

Received 26 February 2004; revised and accepted 11 June 2004 report one case of metastatic pure choriocarcinoma involving the pancreas arising from a regressing testicular mixed germ cell tumor mimicking a primary pancreatic tumor. The cytological, histological, and immunohistochemical features of both the pancreatic and testicular tumor are described, and problems in differential diagnosis are discussed.

\section{Clinical presentation}

A 54-year-old man had a 2-month history of progressive upper abdominal pain and weight loss. His liver function tests were normal at initial presentation. A computed tomography (CT) scan of the abdomen showed a $6 \mathrm{~cm}$ mass in the head of the pancreas (Figure 1). The patient developed jaundice 2 weeks later. His past medical history was notable for coronary artery disease for which he had angioplasty 5 years prior and a 35-year history of 


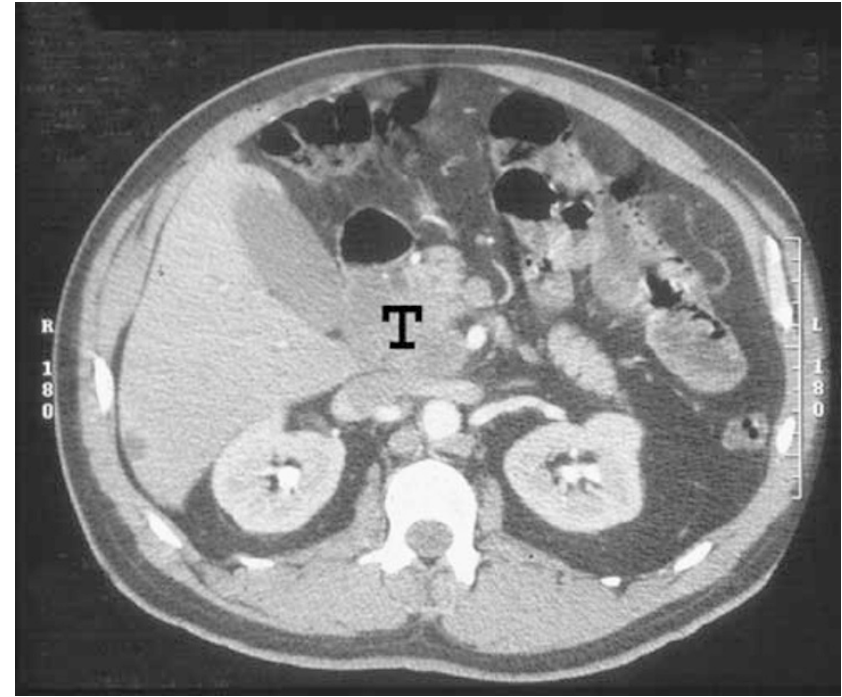

Figure 1 A CT scan of the abdomen demonstrated a $6 \mathrm{~cm}$ mass (T) in the pancreas.

smoking. He also had a history of recurrent epididymitis associated with the presence of a right testicular mass shown to be cystic by ultrasound and stable for at least 10 years. The only relevant family history referred to his father who died of pancreatic cancer at the age of 53 years.

Physical examination revealed a well-nourished man with jaundice, but no peripheral adenopathy or palpable abdominal mass. There was a $3 \mathrm{~cm}$ firm mass in the upper pole of the right testis.

Laboratory findings were remarkable for an elevated alkaline phosphatase of $870 \mathrm{U} / \mathrm{l}$ (reference range 45-115 U/l), asparate aminotransferase of $138 \mathrm{U} / \mathrm{l}$ (reference range $10-40 \mathrm{U} / \mathrm{l}$ ), total bilirubin of $8.1 \mathrm{mg} / \mathrm{dl}$ (reference range $0-1.0 \mathrm{mg} / \mathrm{dl}$ ), direct bilirubin of $6.2 \mathrm{mg} / \mathrm{dl}$ (reference range $0-0.4 \mathrm{mg} / \mathrm{dl}$ ), and the serum tumor maker CA19-9 of $566 \mathrm{U} / \mathrm{ml}$ (reference range $0-36 \mathrm{U} / \mathrm{ml}$ ).

The patient underwent a laparotomy that confirmed a $6 \mathrm{~cm}$ mass in the head of the pancreas with no other lesions or masses seen. An intraoperative biopsy of the pancreatic mass was sent for frozen section which was followed by a pancreaticoduodenectomy (Whipple procedure). The postoperative recovery was uneventful. Pathological examination of the resection specimen was performed in the frozen section room followed by routine histology.
Immediate postoperative follow-up showed $\beta$-human chorionic gonadotropin (HCG) of $295 \mathrm{IU} / \mathrm{l}$ (reference range 0-5 IU/l) and alpha-fetoprotein (AFP) of $4.5 \mathrm{ng} / \mathrm{ml}$ (reference range $<8.5 \mathrm{ng} / \mathrm{ml}$ ). Radiological survey of the patient for masses elsewhere in the body was negative. At 1 week postoperatively, the patient underwent a right orchiectomy. However, 1 month later, the patient's $\beta$-HCG rose to $2973 \mathrm{IU} / \mathrm{l}$, and CT scan showed new retro-crural and pulmonary hilar adenopathies. $\mathrm{He}$ was treated with chemotherapy (four cycles of bleomycin, etoposide, and cisplatin) and his $\beta$-HCG returned to normal and remains so up to his most recent follow-up examination (March, 2004).

\section{Pathological findings}

\section{Pancreas}

\section{Gross morphology}

The pancreaticoduodenectomy specimen consisted of the pancreatic head, proximal duodenum, and distal stomach. An ill-defined $7 \times 6.5 \times 6.0 \mathrm{~cm}$ mass replaced most of the pancreatic head and contained large areas of necrosis and hemorrhage, while viable tan-gray tumor was seen peripherally (Figure 2a). The duodenum and stomach were unremarkable.

\section{Cytomorphology}

Cytological smears of the tumor were made both from the biopsy tissue sent for frozen section as well as from the main resection specimen, and stained with a Romanowsky stain, and a standard Papanicolaou stain.

The cytology smears demonstrated extensive hemorrhage and necrosis. Viable cells were present in cohesive clusters and as single cells. Cells in cohesive clusters were medium to large in size, mitotically active and contained enlarged, round vesicular nuclei and pale, vacuolated cytoplasm with indistinct borders (Figure 2b). A few multinucleated tumor giant cells were also present displaying hyperchromatic, pleomorphic, sometimes bizarre-appearing nuclei with abundant bright blue cytoplasm on the Romanowsky stain (Figure 2c), and dense, amphophilic cytoplasm with the Papanicolaou stain. These overall cytological features were considered consistent with undifferentiated (anaplastic) carcinoma of the pancreas.

\footnotetext{
Figure 2 (a) Grossly, the head of the pancreas was replaced by a large tumor with areas of necrosis and hemorrhage. (b) The cytological smears contained medium to large cells in cohesive clusters and singly. The cells contained nuclei with round, vesicular chromatin and pale, vacuolated cytoplasm with indistinct borders (Papanicolaou, $\times 400)$. (c) Scattered multinucleated tumor giant cells were also present displaying hyperchromatic, pleomorphic, sometimes bizarre-appearing nuclei with abundant bright blue cytoplasm on Romanowsky stain (Diff-Quik, $\times 600$ ). (d) Histologically, small areas with cohesive medium-sized mononuclear cells with amphophilic cytoplasm and moderately pleomorphic nuclei admixed with a few multinucleated cells with abundant eosinophilic cytoplasm, growing focally in a biphasic pattern were seen (hematoxylin and eosin, $\times 100)$. (e) Admixed mononuclear cytotrophoblastic cells and multinucleated syncytiotrophoblast cells focally invaded blood vessels (hematoxylin and eosin, $\times 100$ ). (f) Syncytiotrophoblast cells but not cytotrophoblastic cells focally stained strongly for antibody to HCG (peroxidase-antiperoxidase, $\times 600$ ).
} 

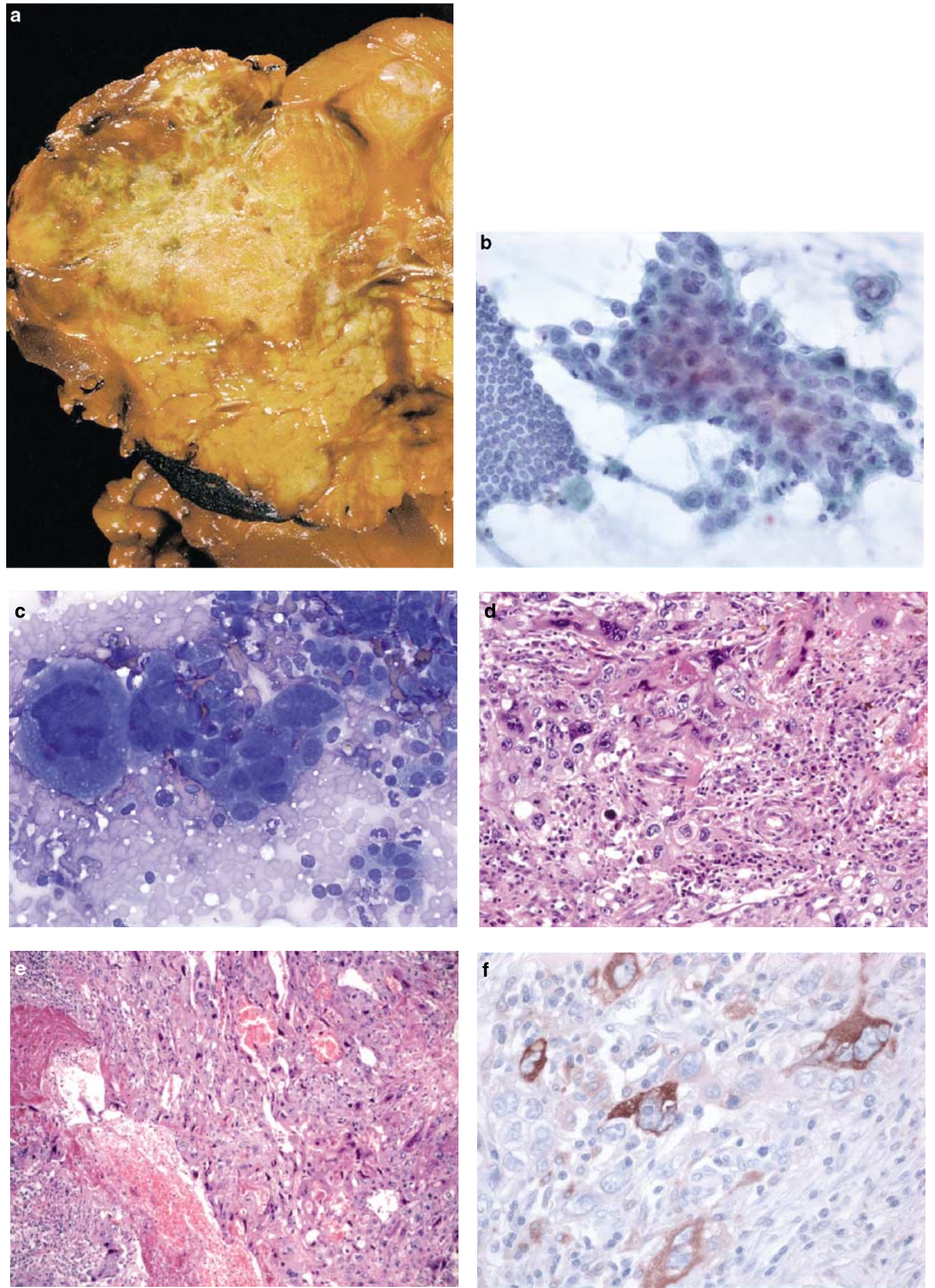


\section{Histology}

The frozen section showed an extensive background of hemorrhage and necrosis, and small areas with cohesive medium-sized mononuclear cells with amphophilic cytoplasm and moderately pleomorphic nuclei admixed with a few multinucleated cells with abundant eosinophilic cytoplasm, growing focally in a biphasic pattern (Figure 2d). A preliminary diagnosis of choriocarcinoma was made. Additional histological sections showed a tumor composed of an intimate admixture of mononuclear cytotrophoblast cells and multinucleated syncytiotrophoblast cells with extensive hemorrhage and necrosis. The mononuclear cells grew in sheets, having large, pleomorphic, single or double nuclei with abundant, well-defined, amphophilic to eosinophilic cytoplasm. The multinucleated cells had abundant eosinophilic cytoplasm with irregular, pleomorphic, sometimes hyperchromatic nuclei focally coating the mononucleated cells. Mitotic figures were frequent. Extensive vascular invasion by multinucleated syncytiotrophoblast cells was also present (Figure 2e). After extensive sectioning of the tumor, only an additional small focus of mature cartilage was found, suggesting a minor teratomatous component of the neoplasm. No areas of conventional pancreatic carcinoma or intraepithelial neoplasia were identified.

\section{Immunohistochemistry}

The following immunohistochemical stains were performed on the pancreatic tumor: pan-cytokeratin (AE1.3/CAM5.2), cytokeratin 19 (CK19), vimentin, HCG, human placental lactogen (HPL), AFP, carcinoembryonic antigen (CEA), inhibin, and S100 using a standard avidin-biotin-antiperoxidase technique and antigen retrieval.

Staining showed the tumor cells to be strongly and diffusely positive for pancytokeratin (AE1.3/ Cam5.2). Many of the syncytiotrophoblast cells stained strongly for HCG (Figure 2f), but the cytotrophoblastic cells were negative. With antibody to inhibin, there was focal strong staining of syncytiotrophoblast cells. The tumor was negative for CEA, S100, CK19, vimentin, AFP, and HPL.

\section{Fluorescence in situ hybridization (FISH) study}

To evaluate the presence of isochromosome (12p), a common chromosomal abnormality seen in germ cell tumors, FISH analysis was performed on interphase nuclei isolated from formalin-fixed paraffin-embedded tissue using TEL and D12Z3 probes (Vysis, Inc. Downers Grove, IL, USA) as described elsewhere. ${ }^{11}$

No fluorescence signals of isochromsome (12p) were identified in 30 nuclei examined.

\section{Testis}

\section{Gross morphology}

The right testis was bivalved and revealed a $2.5 \times 2.2 \times 1.8 \mathrm{~cm}$ ill-defined, predominantly cystic and partially solid lesion, focally abutting the tunica albuginea (Figure 3a). The dominant cyst measured $2.2 \mathrm{~cm}$, had a smooth tan lining and contained pasty green and brown material. A second small, hemorrhagic, $0.5 \mathrm{~cm}$ cyst was also present in the wall of the larger cyst. The solid area was light brown and homogeneous in appearance.

\section{Cytomorphology}

The tumor was aspirated using a 23-gauge needle anticipating a solid tumor but drained $3 \mathrm{ml}$ of yellow, turbid fluid. The fluid was smeared on slides, allowed to air dry, and stained with a Romanowsky stain. Smears of the aspirated fluid demonstrated acute inflammatory cells, hemosiderin-laden macrophages, and multinucleated giant
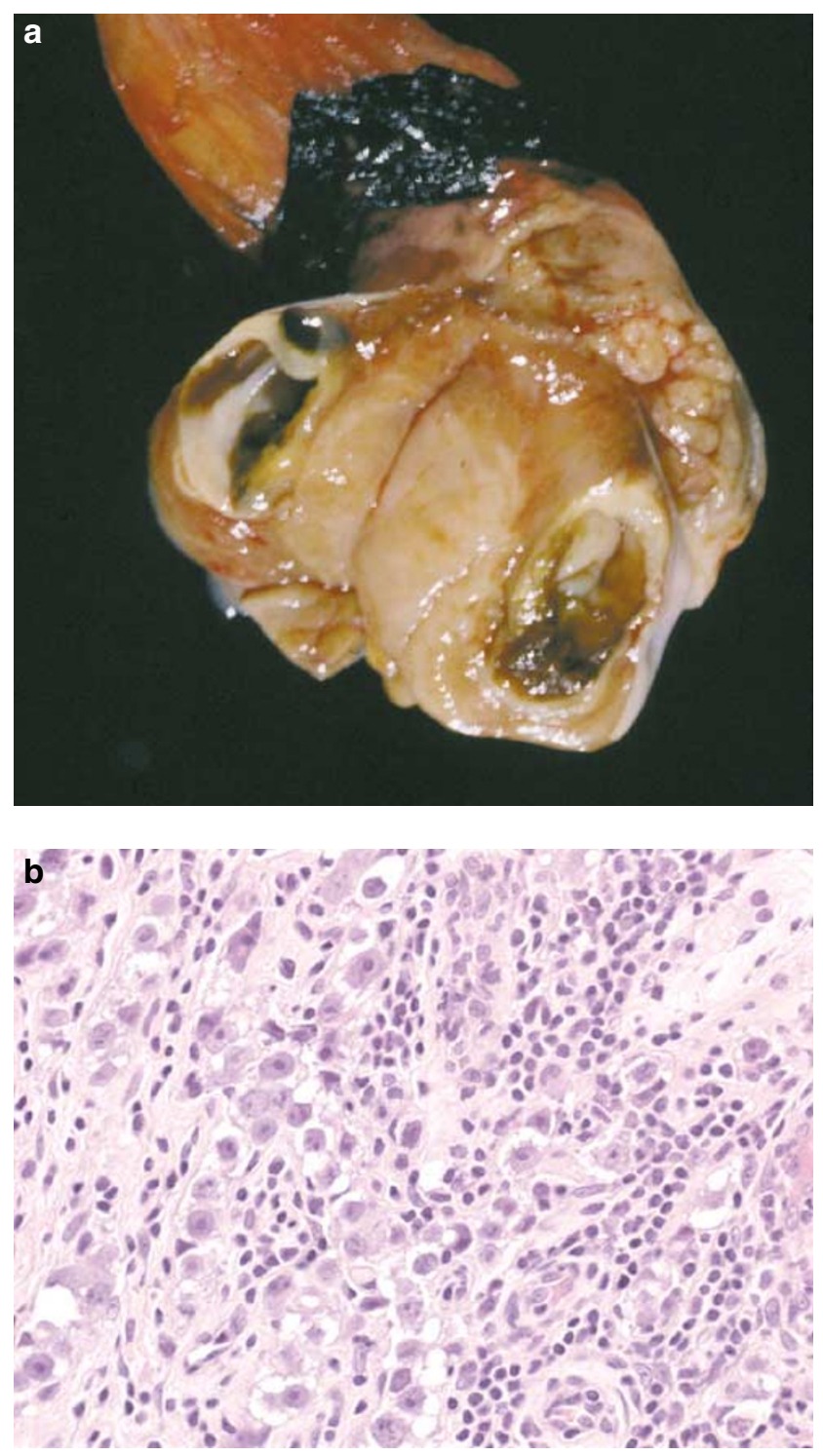

Figure 3 (a) Ill-defined, predominantly cystic lesion focally abutting the tunica albuginea. (b) Large round cells with central nuclei, prominent nucleoli and mostly clear cytoplasm defined a component of seminoma in the testicular germ cell tumor (hematoxylin and eosin, $\times 400$ ). 
cells with scattered atypical cells thought to represent reactive stromal cells from the cyst lining or wall. No definitive malignant cells were identified.

\section{Histology}

On routine microscopic examination, the solid area of the tumor was composed predominately of nests of cells with round to polygonal nuclei with one or more prominent nucleoli, and clear to eosinophilic, granular cytoplasm, separated by thin fibrous septae containing a moderate lymphocytic infiltrate (Figure 3b). The neoplastic cells focally showed pagetoid spread to the rete testis with focal minimal extension into the tunica albuginea. The cystic areas were composed of cystically dilated glands, lined by intestinal-type epithelium. One cyst was partially ruptured, surrounded by reparative granulation tissue. Finally, an area of scarring with dense deposits of collagen and hemosiderin-laden macrophages was also identified. Lymphatic invasion was present. A component of unclassified intratubular germ cell neoplasia, was also seen adjacent to the main tumor mass. No choriocarcinoma or other germ cell components were identified. Based on these findings, a final diagnosis of a regressing mixed germ cell tumor with areas of seminoma and teratoma was made.

\section{Discussion}

Nonseminomatous germ cell tumors are highly aggressive malignant tumors of the testis. Many of the patients show metastatic disease at presentation. Histologically, approximately $70 \%$ of the nonseminomatous germ cell tumors are composed of more than one germ cell component (mixed germ cell tumor). ${ }^{12}$ Among various components including embryonal carcinoma, seminoma, yolk sac tumor, and teratoma, choriocarcinoma is relatively rare. Less than $8 \%$ of the testicular germ cell tumors contain a component of choriocarcinoma, and pure choriocarcinoma accounts for only $0.3 \%$ of the primary testicular germ cell tumors. ${ }^{13}$ The usual mode of presentation in a testicular mixed germ cell tumor is testicular enlargement, sometimes with pain, but may vary depending on the tumor components, with greater propensity for distant metastases in tumors with high-risk histology, particularly choriocarcinoma. Testicular choriocarcinoma often presents with early and widespread hematogenous metastatic disease. The most common presenting symptoms include hemoptysis secondary to pulmonary metastases, back pain secondary to retroperitoneal spread, gastrointestinal bleeding due to gastrointestinal tract metastases, and neurological symptoms from brain metastases. ${ }^{13}$ Metastatic choriocarcinoma to the pancreas presenting as a primary tumor is extremely rare with only one reported case in the literature. ${ }^{9}$
In our case, the clinical presentation of jaundice and a large solitary metastasis to the pancreas without involvement of common sites, such as the lung, gastrointestinal tract, or brain, was exceedingly unusual and supported the initial clinical impression of a primary pancreatic tumor. This impression was further supported by the absence of noticeable changes during a 10-year interval in the testicular mass and by the first-degree family history of pancreatic cancer.

Ductal adenocarcinoma is the most common neoplasm of the pancreas, representing $85-90 \%$ of all pancreatic neoplasms, with an annual incidence of 3.1-20.8 per 100000 males and 2.0-22.0 per 100000 female patients in developed countries. ${ }^{14}$ Approximately $80 \%$ of cases occur in patients in the seventh or eighth decades, with a slight male dominance and blacks having a distinctly higher incidence than whites. ${ }^{15} \mathrm{~A}$ combination of imaging studies including ultrasonography (US), CT or magnetic resonance imaging (MRI), with fine-needle aspiration biopsy (FNAB) and tumor marker analysis (CEA) have achieved a more than 95\% accuracy rate for diagnosis. ${ }^{16}$ The role of preoperative FNAB in the assessment of pancreatic masses is well established. ${ }^{17-21}$ Typical pancreatic carcinomas usually do not pose problems in diagnosis in cytology. However, the differential diagnosis of choriocarcinoma from a poorly differentiated pancreatic carcinoma, particularly undifferentiated (anaplastic) carcinoma may be very challenging, even more so if the typical biphasic pattern of syncytiotrophoblast and cytotrophoblast cells of choriocarcinoma is absent or unappreciated, as was the case in this patient. The simultaneous frozen section precluded a misclassification of the neoplasm. Undifferentiated carcinoma of the pancreas accounts for approximately $2-7 \%$ of the primary pancreatic carcinomas, and is composed of large, bizarre, eosinophilic cells and/or ovoid to spindle-shaped cells that grow in a poorly cohesive manner. Mitotic activity is usually high and perineural, lymphatic, and blood vessel invasion is almost always present. Cytophagocytosis may be seen. ${ }^{14}$ On cytological examination, the malignant cells usually recapitulate these histological features, showing a loosely cohesive to dispersed single-cell population of large, bizarre mononuclear, multinuclear, and spindled cells with frequent mitotic activity and 'cannibalism'. Benign appearing osteoclast-type giant cells may occasionally be present. ${ }^{2-24}$ In contrast, choriocarcinoma is composed of two cell types: syncytio- and cytotrophoblast cells. The former are large multinucleated cells with eosinophilic cytoplasm, hyperchromatic, sometimes bizarre, nuclei with distinct nucleoli; while the latter are medium-sized cells with indistinct cell borders, vacuolated, basophilic cytoplasm, and eccentric nuclei, arranged in loose clusters or as single cells. ${ }^{25}$ The distinction of choriocarcinoma from undifferentiated pancreatic carcinoma may be 
impossible by cytomorphology alone. The pleomorphic cytotrophoblast cells of the choriocarcinoma may be indistinguishable from the pleomorphic large cells of an undifferentiated carcinoma. Bizarre, multinucleated giant cells may be seen in both neoplasms. In addition, some undifferentiated carcinomas may contain a few scattered syncytiotrophoblast cells. However, on histological examination, the typical intimate admixture of cytotrophoblast cells and syncytiotrophoblast cells, the extensive hemorrhage with the characteristic vascular invasion by the syncytiotrophoblast cells, and the absence of appreciable glandular differentiation are all features that supported a diagnosis of choriocarcinoma. Immunohistochemical studies can be very helpful in this differential diagnosis. Undifferentiated pancreatic carcinoma cells are usually positive for vimentin, and in many cases may also be positive for epithelial markers including CEA, pancytokeratin and/or CK 19 , but they are negative for inhibin, $\beta$-HCG, and HPL. In contrast, choriocarcinoma is diffusely and strongly positive for pancytokeratin, and most importantly, the syncytiotrophoblast cells are positive for $\beta$-HCG, inhibin, and/or weakly positive for HPL. It is worth noting, however, that many gastrointestinal carcinomas, including cholangiocarcinoma, gastric, and pancreatic adenocarcinoma may have positive immunohistochemical staining of the $\beta$-HCG antibody, ${ }^{26}$ and/or elevated serum HCG levels. ${ }^{27,28}$ Furthermore, overt choriocarcinomatous differentiation has been reported in rare cases of carcinomas of the stomach, ${ }^{29}$ lung, ${ }^{30}$ colon, ${ }^{31}$ renal pelvis, ${ }^{32}$ urinary bladder, ${ }^{33}$ endometrium, ${ }^{34}$ ovary, ${ }^{35}$ and pancreas. ${ }^{7}$ In these reported cases, exhaustive sectioning of the tumor to demonstrate an associated unequivocal primary carcinomatous component was required for the diagnosis, and a metastasis from a primary germ cell tumor was excluded clinically.

Finally, pure nongestational choriocarcinoma can also rarely occur in extragonadal primary sites. These tumors are uncommon and typically occur in young men of 20-35 years. Most tumors arise in midline structures, such as the retroperitoneum, mediastinum, and in the vicinity of the pineal gland, but they also have been reported in other visceral organs such as the lung, stomach, esophagus, small bowel, prostate, and urinary bladder. ${ }^{36}$ Primary choriocarcinoma of the pancreas is very rare with only two cases reported previously in the literature, one in an inflammatory pseudocyst ${ }^{6}$ and the other present on CT as a cystic tumor in the pancreatic tail. ${ }^{8}$ Several theories explaining the pathogenesis of these extragonadal choriocarcinomas have been proposed. One hypothesis is that the tumors arise from the primordial germ cells that migrate abnormally during embryonic development; ${ }^{37}$ another theory postulates development of these tumors secondary to dedifferentiation or neometaplasia of nongonadal tissue. ${ }^{38}$ Still others, favor that extragonadal nongestational choriocarcinoma indeed represents a metastasis from a spontaneously regressed primary gonadal germ cell tumor. $^{39}$

Isochromosome $12 \mathrm{p}$ is the only consistent structural abnormality of germ cell tumors. However, it is unclear if it is restricted to one specific subtype or is present in all subtypes. Only rare cases of genetic analyses on pure choriocarcinoma have been reported. Bettio et $a l^{11}$ did not observe any i(12p) on direct cytogenetic analysis of a gestational choriocarcinoma. One pure choriocarcinoma of the bladder has been reported to have the i(12p) by FISH analysis, but no details of the probes used for such analysis were provided by the authors. ${ }^{40}$ Comparative genomic hybridization studies from 12 archival cases of choriocarcinomas have revealed chromosomal imbalance such as amplification of 7q21-q31 (four cases) and loss 8p12-p21 (five cases), but no evidence of amplification of $12 p$ was observed. ${ }^{41}$

In our particular case, while the clinical presentation favored a primary pancreatic tumor, the subsequent histological confirmation of the diagnosis of choriocarcinoma with a minor component of cartilage in the pancreas led to further investigation of the testicular mass. The resected testis showed a mixed germ cell tumor, composed predominantly of seminoma with a small component of teratoma in a background of scarring, with no histological evidence of choriocarcinoma suggesting that the choriocarcinomatous component may have regressed. The concept of spontaneous regression in testicular germ cell tumors has been established based on studies of patients who died of metastatic germ cell tumor and were found to have testicular abnormalities only at autopsy. ${ }^{42,43}$ Some studies have suggested that patients with metastatic choriocarcinoma had the highest rate of regressed primary testicular lesions. ${ }^{44}$ An alternative explanation of the histological discrepancy between the types of germ cell tumor present in the testis and in the metastasis is transformation into other types of germ cell neoplasia when the tumor metastasizes and this phenomenon has been well documented. ${ }^{45,46}$

The metastatic nature of the pancreatic tumor in this case is further supported by the evidence of an elevated $\beta$-HCG level and pulmonary hilar lymph node metastases soon after resection of the pancreatic mass, although this cannot completely exclude the possibility of a primary high grade pancreatic tumor with a choriocarcinomatous component. The management of metastatic lesions to the pancreatic head and periampullary region had been mostly non-operative in the past; however, recent evidence suggests that pancreaticoduodenectomy could be a rational option for patients with a metastatic tumor confined to the pancreatic head due to greatly decreased postoperative morbidity and mortality. ${ }^{47}$

In summary, we present a rare case of a metastatic testicular mixed germ cell tumor that presented as a 
primary pancreatic tumor composed almost exclusively of choriocarcinoma. Cytological evaluation alone would have likely suggested undifferentiated carcinoma of the pancreas given the cytological similarities of the two neoplasms and the clinical presentation of the patient, but the typical histological appearance allowed for the correct diagnosis.

\section{References}

1 Saigo PE, Brigati DJ, Sternberg SS, et al. Primary gastric choriocarcinoma. An immunohistological study. Am J Surg Pathol 1981;5:333-342.

2 Matthews TH, Heaton GE, Christopherson WM. Primary duodenal choriocarcinoma. Arch Pathol Lab Med 1986;110:550-552.

3 Harada N, Misawa T, Chijiiwa Y, et al. A case of extragenital choriocarcinoma in the jejunum. Am J Gastroenterol 1991;86:1077-1079.

4 Brunner J, Hogberg T, Malmstrom H, et al. Postmenopausal extragenital choriocarcinoma. A case report and review of the literature. Eur J Gynaecol Oncol 1991;12:395-398.

5 Bjornsson J, Scheithauer BW, Leech RW. Primary intracranial choriocarcinoma: a case report. Clin Neuropathol 1986;5:242-245.

6 Childs CC, Korsten MA, Choi HS, et al. Pancreatic choriocarcinoma presenting as inflammatory pseudocyst. Gastroenterology 1985;89:426-431.

7 Zamboni G, Boneti F, Castelli P, et al. Mucinous cystic tumor of the pancreas recurring after 11 years as cystadenocarcinoma with foci of choriocarcinoma and osteoclast-like giant cell tumor. Surg Pathol 1994;5: 253-262.

8 Coskun M, Agildere AM, Boyvat F, et al. Primar choriocarcinoma of the stomach and pancreas: CT findings. Eur J Radiol 1998;8:1425-1428.

9 Gonzalez Garcia M, Aldrete JS. Cystic neoplasms of the pancreas: report of 3 cases presenting diagnostic difficulties. Rev Invest Clin 1995;47:43-48.

10 Tinkle LL, Graham BS, Spillane TJ, et al. Testicular choriocarcinoma metastatic to the skin: an additional case and literature review. Cutis 2001;67:117-120.

11 Bettio D, Giardiano D, Rizzi N, et al. Cytogenetic abnormalities detected by direct analysis in a case of choriocarcinoma. Cancer Genet Cytogenet 1993;68: 149-151.

12 Jacobsen GK, Barlebo H, Olsen J. Testicular germ cell tumours in Denmark 1976-1980. Pathology of 1058 consecutive cases. Acta Radiol Oncol 1984;23: 239-247.

13 Ulbright TM, Mahal BA, Young RH. Tumors of the testis, adnexa, spermatic cord, and scrotum. In: Rosai J (ed). Atlas of Tumor Pathology. Armed Forces Institute of Pathology: Washington, DC: 1999.

14 Klöppel G, Hruban R, Longnecker DS, et al. Tumours of the exocrine pancreas. In: Hamilton SR, Aaltonen LA (eds). WHO Classification of Tumours-Pathology and Genetics of Tumours of the Digestive System. IARC Press: Lyon, 2000, pp 219-252.

15 Gold EB, Goldin SB. Epidemiology of and risk factors for pancreatic cancer. Surg Oncol Clin N Am 1998; 7:67-91.
16 Warshaw AL, Fernández-Del Castillo C. Pancreatic carcinoma. N Engl J Med 1992;326:455-465.

17 Wiersema MJ, Vilmann P, Giovannini M, et al. Endosonography-guided fine-needle aspiration biopsy: Diagnostic accuracy and complication assessment. Gastroenterology 1997;112:1087-1095.

18 Cahn M, Chang K, Nguyen $\mathrm{P}$, et al. Impact of endoscopic ultrasound with fine-needle aspiration on the surgical management of pancreatic cancer. Am J Surg 1996;172:470-472.

19 Chang KJ, Nguyen P, Erickson RA, et al. The clinical utility of endoscopic ultrasound-guided fine-needle aspiration in the diagnosis and staging of pancreatic carcinoma. Gastrointest Endosc 1997;45: 387-393.

20 Williams DB, Sahai AV, Aabakken L, et al. Endoscopic ultrasound guided fine needle aspiration biopsy: a large single centre experience. Gut 1999;44: 720-726.

21 Brugge WR. Endoscopic ultrasound-guided pancreatic fine-needle aspiration: a review. Techn Gastrointest Endosc 2000;2:149-154.

22 Silverman JF, Dabbs DJ, Finley JL, et al. Fine-needle aspiration biopsy of pleomorphic (giant cell) carcinoma of the pancreas. Cytologic, immunocytochemical, and ultrastructural findings. Am J Clin Pathol 1988; 89:714-720.

23 Pinto MM, Monteiro NL, Tizol DM. Fine needle aspiration of pleomorphic giant-cell carcinoma of the pancreas. Case report with ultrastructural observations. Acta Cytol 1986;30:430-434.

24 Mullick SS, Mody DR. Osteoclastic giant cell carcinoma of the pancreas. Report of a case with aspiration cytology. Acta Cytol 1996;40:975-979.

25 Chao TY, Nieb S, Huang SH, et al. Cytology of fine needle aspirates of primary extragonadal germ cell tumors. Acta Cytol 1997;41:497-503.

26 Louhimo J, Nordling S, Alfthan H, et al. Specific staining of human chorionic gonadotropin beta in benign and malignant gastrointestinal tissues with monoclonal antibodies. Histopathology 2001;38:418-424.

27 Ishikawa H, Tsutsumi HMI, Yoshida H, et al. Undifferentiated carcinoma of the pancreas with choriocarcinomatous feature producing human chorionic gtonadotropin. Gan No Rinsho 1986;32:1041-1045.

28 Syrigos KN, Fyssas J, Konstandoulakis MM, et al. Beta human choionic gonadotropin concentration in serum of patients with pancreatic adenocarcinoma. Gut 1998; 42:88-91.

29 Mori H, Soeda O, Kamano K, et al. Choriocarcinomatous change with immunohistochemically HCG-positive cells in the gastric carcinoma of the males. Virch Arch 1982;396:141-153.

30 Ikura $\mathrm{Y}$, Inoue $\mathrm{T}$, Tsukuda $\mathrm{H}$, et al. Primary choriocarcinoma and human chorionic gonadotropinproducing giant cell carcinoma of the lung: are they independent entities? Histopathology 2000; 36:17-25.

31 Nguyen GK. Adenocarcinoma of the sigmoid colon with focal choriocarcinoma metaplasia: a case report. Dis Colon Rectum 1982;25:230-234.

32 Zettl A, Konard MA, Polzin S, et al. Urothelial carcinoma of the renal pelvis with choriocarcinomatous features: genetic evidence of clonal evolution. Hum Pathol 2002;33:1234-1237.

33 Grammatico D, Grignon DJ, Eberwein $\mathrm{P}$, et al. Transitional cell carcinoma of the renal pelvis with choriocarcinomatous differentiation: immunohistochemical and immunoelectron microscopic 
assessment of human chorionic gonadotropin production by transitional cell carcinoma of the urinary bladder. Cancer 1993;71:1835-1841.

34 Savage J, Subby W, Okagaki T. Adenocarcinoma of the endometrium with trophoblastic differentiation and metastases as choriocarcinoma: a case report. Gynecol Oncol 1987;26:257-262.

35 Oliva E, Andrada E, Pezzica E, et al. Ovarian carcinomas with choriocarcinomatous differentiation. Cancer 1993;72:2441-2446.

36 Hainsworth JD, Greco FA. Extragonadal germ cell tumors and unrecognized germ cell tumors. Semin Oncol 1992;19:119-127.

37 Fine G, Smith RW, Pachter MR. Primary extragenital choriocarcinoma in the male subject. Am J Med 1962;32:776-794.

38 Sullivan LG. Primary choriocarcinoma of the lung in a man. Arch Pathol Lab Med 1989;113:82-83.

39 Bohle A, Studer UE, Sonntag RW, et al. Primary or secondary extragonadal germ cell tumors? J Urol 1986;135:939-943.

40 Hanna NH, Ulbright TM, Einhorn LH. Primary choriocarcinoma of the bladder with the detection of isochromosome 12p. J Urol 2002;167:1781.
41 Ahmed MN, Kim K, Haddad B, et al. Comparative genomic hybridization studies in hydatidiform moles and choriocarcinoma: amplification of 7q21-q31 and loss of 8p12-q21 in choriocarcinoma. Cancer Genet Cytogenet 2000;116:10-15.

42 Rottinto A, DeBellis H. Extragenital chorioma: its relation to teratoid vestiges in the testicles. Arch Pathol 1944;37:78-80.

43 Azzopardi JG, Mostofi FK, Theiss EA. Lesions of the testes observed in certain patients with widespread choriocarcinoma and related tumors. Am J Pathol 1961;38:207-225.

44 Lopez JI, Angulo JC. Burned-out tumour of the testis presenting as retroperitoneal choriocarcinoma. Int Urol Nephrol 1994;26:549-553.

45 Bar W, Hedinger C. Comparison of histologic types of primary testicular germ cell tumors with their metastases: consequences for the WHO and the British nomenclatures? Virch Arch 1976;370:41-54.

46 Crook JC. Morphogenesis of testicular tumours. J Clin Pathol 1968;21:71-74.

47 Medina-Franco H, Helpern NB, Aldrete JS. Pancreaticoduodenectomy for metastatic tumors to the periampullary region. J Gastrointest Surg 1999;3:119-122. 